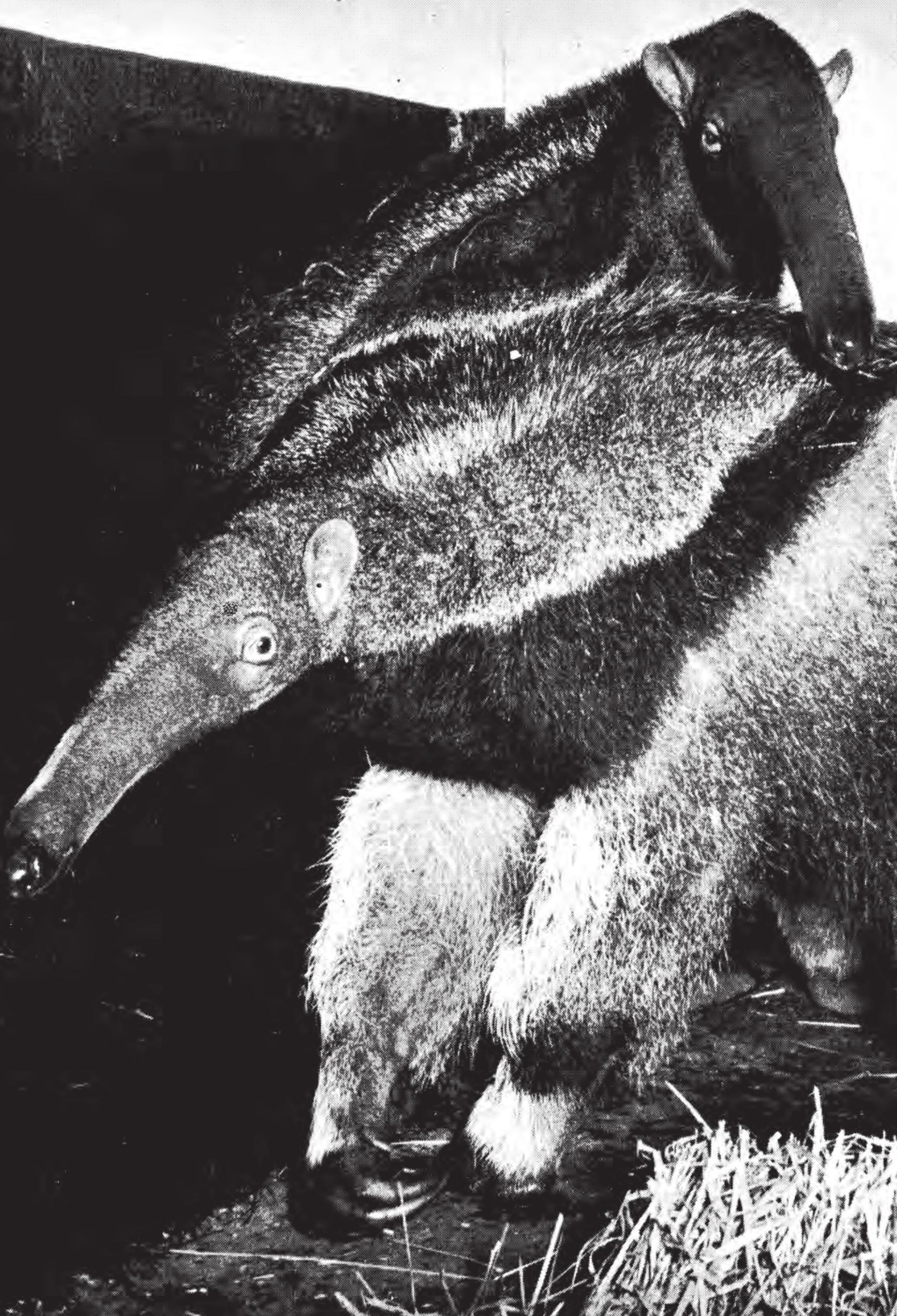




\title{
REDES DE APOIO SOCIAL NO RIO DE JANEIRO E EM SÃO PAULO
}

\author{
EDUARDO MARQUES E RENATA BICHIR
}

\section{RESUMO}

$\mathrm{O}$ artigo analisa como indivíduos residentes no Rio de Janeiro e em São Paulo mobilizam seus vínculos mais próximos para obter auxílios cotidianos e empregos e para enfrentar crises de saúde. Utilizando dados de survey realizado em 2008, dá continuidade à investigação anterior sobre redes pessoais em São Paulo. O artigo analisa as principais características, dinâmicas e condicionantes, das redes egocentradas, mostrando fortes regularidades baseadas no ciclo de vida e nas diferenças entre grupos sociais. Apesar disso, os resultados indicam intensa heterogeneidade no interior de cada grupo, organizada, tanto para pobres quanto para não pobres, pela homofilia e pelo localismo das redes, com fortes consequências para a reprodução das desigualdades sociais.

PALAVRAS-CHAVE: Redes pessoais; redes egocentradas; apoio social; desigualdade.

\section{ABSTRACT}

This article analyzes egocentered networks of social support in Rio de Janeiro and São Paulo using data from a survey carried out in 2008. Following the results of a previous research about personal networks in São Paulo, we investigate the main characteristics, dynamics and conditioning factors of the networks, evidencing strong regularities along the life cycle and between social groups. Regardless of those regularities, the results indicate intense relational heterogeneity inside each social group, organized both among the poor and the non-poor by the homophily and localism of the networks, generating strong consequences for the reproduction of social inequalities.

KEYWORDS: Personal networks; egocentered networks; social support; inequalities.

[1] Como não foram encontradas diferenças significativas entre as redes egocentradas de apoio social nas duas cidades, a maior parte das análises agrupa as duas, salvo quando há indicações contrárias.
Os padrões de relação em que se inserem os indivíduos têm sido associados, na literatura internacional e brasileira, aos mais variados fenômenos. O presente artigo visa contribuir para o entendimento da importância das redes na sociabilidade cotidiana dos indivíduos, analisando as redes de apoio social no cotidiano, na busca de emprego e em crises de saúde no Rio de Janeiro e em São Paulo em período recente ${ }^{1}$. Os resultados são originários de survey realizado pelo Centro de Estudos da Metrópole (CEM-Cebrap) e pelo IUPERJ (atual IESP-UERJ) em 2008, com 1.744 pessoas nas duas cidades. A amostra foi desenhada para representar o conjunto da população, mas também os $40 \%$ mais pobres de cada cidade. 
O artigo dá continuidade a uma agenda de pesquisa preocupada em explorar o papel das redes de relações sociais nas condições de vida em metrópoles, particularmente entre os mais pobres ${ }^{2}$, seguindo debates presentes na literatura internacional ${ }^{3}$. Em pesquisa anterior ${ }^{4}$, analisamos as redes pessoais de 209 indivíduos em situação de pobreza em sete diferentes locais na metrópole de São Paulo, replicando posteriormente a pesquisa para outras 153 redes em Salvador ${ }^{5}$. Trabalhando com as redes totais dos indivíduos, o estudo mostrou a centralidade das redes na mediação do acesso a bens e serviços obtidos em mercados e fora deles, como acesso a emprego, inclusive de melhor qualidade (emprego com carteira assinada), obtenção de apoios e auxílios sociais, presença de maior ou menor precariedade social e obtenção de rendimentos monetários.

O presente artigo testa de forma estatisticamente representativa os principais elementos encontrados anteriormente, assim como discute os principais condicionantes das redes, cruzando suas características com atributos dos indivíduos, como idade, sexo, renda, escolaridade e status migratório.

O artigo é organizado em três seções, além desta introdução e da conclusão. Na próxima seção, resenhamos brevemente a literatura sobre redes egocentradas. Em seguida, apresentamos a metodologia da pesquisa e as principais características e dinâmicas que cercam as redes, indicando a existência de padrões claros referentes ao ciclo de vida dos indivíduos e aos grupos sociais aos quais pertencem. Apesar disso, as redes apresentam grande heterogeneidade, inclusive no interior de cada grupo social. A terceira seção explora essa heterogeneidade desenvolvendo uma tipologia das redes, claramente associadas à presença de localismo e homofilia, confirmando as hipóteses iniciais da pesquisa.

\section{REDES SOCIAIS E SUAS CARACTERISTICAS}

Esta seção apresenta elementos conceituais importantes, principalmente entre redes pessoais e redes egocentradas, sem pretender resenhar a literatura do tema ${ }^{6}$. As redes egocentradas representam um recorte analítico das redes pessoais dos indivíduos. O seu estudo não parte de considerações ontológicas individualistas sobre os padrões de relação, mas de uma restrição produzida pelo método das redes de sociabilidade mais amplas. Conceitualmente, portanto, redes egocentradas são redes pessoais, mas centradas no ego e com distância máxima de um passo a partir dele.

O estudo de redes pessoais parte do conjunto de contatos de um dado indivíduo em sua sociabilidade, incluindo vínculos diretos e indiretos (os amigos e os amigos dos amigos, por exemplo), utilizando
[2] Marques, Eduardo. Redes sociais, pobreza e segregação em São Paulo. São Paulo: Ed. Unesp/CEM, 2010.

[3] Briggs, Xavier (org.).The Geography of opportunity: Race and Housing Choice in Metropolitan America. Washington, DC: Brookings Institution Press, 2005; Blokland, Talya e Savage, Mike. Networked urbanism: social capital in the city. Londres: Ashgate, 2008; e Mustered, Sako, Murie, Alain e Kestellot, C. Neighborhoods of poverty: urban social exclusion and integration in Europe. Londres: Palgrave, 2006.

[4] Marques, E., op.cit.

[5] Marques, E., Bichir, Renata, Moya, Encarnación e Castello, Graziela. "Redes sociais, pobreza e espaço em duas metrópoles brasileiras". In: Baeninger, Rosana (org.). População e cidades: subsídios para o planejamento e para as políticas sociais. Campinas: Editora Unicamp/ Unfa/ Nepo, 2010.

[6] Para referências técnicas gerais, ver Wasserman, Stanley e Faust, Katherine. Social Network Analysis: Methods and Applications. Cambridge: Cambridge University Press, 1994, e Hanneman, Robert e Riddle, Mark. Introduction to social network methods. 〈http://faculty.ucr. edu/ hanneman/>, acessado em 21/06/2011. Para uma história da análise de redes, ver Freeman, Linton. The development of social network analysis. Vancouver: Empirical Press, 2004. 
[7] Os dados para estudarmos redes são usualmente cognitivos, sendo, portanto, fortemente influenciados pela percepção que indivíduos diferentes têm sobre suas relações. Longe de representar uma limitação, essa informação nos fornece exatamente os dados de que precisamos, já que os indivíduos utilizam as redes da forma como as compreendem.
[8] Beggs, J. “ Revising the rural-urban contrast - personal networks in nonmetropolitan and metropolitan settings". Rural sociology, 61, 1996, pp. 306-25, e Moore, Gwen. "Structural determinants of men's and women's personal networks". Annual Sociological Review, vol. $55, \mathrm{n}^{\circ} 5,1990$, pp. 726-35.

[9] Fischer, Claude e Shavit, Y. "National differences in network density: Israel and the United States". Social Networks, 17, 2, 1995, pp. 129-45, e Grossetti, Michel. "Are French networks different?". Social Networks, 29,3, 2007, pp.391-404.

[10] Lonkila, M. “The importance of work-related social ties in post-soviet Russia: the role of co-workers in the personal networks in St. Petersburg and Helsinki". Connections, vol. 30 , 1, 2010, pp. 46-56, p. 47. Todos os excertos em inglês foram traduzidos livremente pelos autores. geradores de nomes e técnicas de bola de neve7. A aplicação de tais métodos permite levantar redes grandes e que circunscrevem situações sociais inteiras. Entretanto, as ferramentas e o método empregados tornam extremamente difícil a aplicação desse tipo de pesquisa para grandes grupos populacionais, mesmo através de técnicas de amostragem. Por essa razão, esse tipo de investigação leva a desenhos de pesquisa baseados em estudos de caso com escolha intencional, seguidos de saturação das situações existentes para a análise da variação dos resultados. Como em todos os casos de aplicação desse tipo de desenho, aprendemos muito sobre os detalhes das situações e sobre os efeitos da combinação dos elementos envolvidos, mas a capacidade de generalização dos padrões encontrados é menor.

Diferentemente, as redes egocentradas podem ser obtidas a partir de surveys, gerando resultados estatisticamente significativos para grandes populações. Nesse caso, os entrevistados são instados a listar os seus contatos imediatos para dada ajuda, resolução de problema ou situação social, mas sem que se descubra como esses contatos se desdobram em outros, localizados mais distantes do ego. Pesquisas por amostragem regulares podem incluir esse tipo de informação, possibilitando inclusive a realização de painéis sobre os contatos presentes em dada sociedade, como no caso do General Social Survey norte-americano, realizado regularmente desde $1972^{8}$.

A despeito da relevância das redes egocentradas em diversas comparações internacionais 9 , estamos de acordo com a crítica que Lonkilla ${ }^{10}$ endereça a essas pesquisas: "Esses surveys não incluem dados sobre as interconexões entre os alters e, nesse sentido, não permitem a análise da estrutura das redes pessoais". Dado que uma parte importante dos elementos materiais e imateriais circula nas redes a distâncias maiores que um passo, o estudo das redes egocentradas desconsidera informações sobre muitas dimensões sociais, embora permita maior generalidade nos resultados. Além disso, esse tipo de dado permite entender melhor padrões de ajuda e reciprocidade em momentos de necessidade que podem ocorrer de forma não mediada, por meio de vínculos diretos. Assim, resultados obtidos através de redes egocentradas e aqueles obtidos através de redes pessoais não são diretamente comparáveis, embora certas tendências possam ser testadas.

Uma parte significativa dos elementos disponíveis para análise diz respeito a atributos dos indivíduos presentes nas redes, além do seu tamanho, sendo a homofilia uma das dimensões mais importantes. Homofilia é a característica de uma relação que descreve a coincidência de atributos entre os indivíduos. Nesse sentido, existem muitos tipos de homofilia, tantos quantos forem os atributos considerados, por exemplo: relação homofílica de sexo é relação de pessoas do mes- 
mo sexo e relação racial homofílica é entre pessoas que se reconhecem como pertencendo à mesma raça ${ }^{11}$. A homofilia é considerada importante, pois relações entre indivíduos com atributos diferentes tendem a veicular mais frequentemente informação e recursos materiais e imateriais não redundantes ${ }^{12}$.

Em termos específicos, podemos calcular o grau de homofilia presente em uma rede com relação a certo atributo a partir da informação de cada díade, considerando a proporção das relações presentes nessa rede que envolve díades com atributos iguais. No entanto, na ausência de informações específicas sobre os vários atributos dos indivíduos que compõem uma rede, podemos presumir as características gerais de homofilia de uma rede utilizando outras informações que estão usualmente associadas à presença de atributos similares nas díades, como a presença de parentes e vizinhos — vínculos que muitas vezes tendem a ter características próximas às do ego-, ou o localismo. O localismo diz respeito à proporção da rede que habita próximo ao ego, sugerindo maior ou menor circulação geográfica, assim como o pertencimento a esferas de sociabilidade geograficamente distantes ou próximas.

Outra dimensão importante no entendimento das redes sociais é a multiplicidade. Isso ocorre quando uma pessoa é citada por um ego como participando de mais de uma de suas redes e/ou esferas de sociabilidade. Qual o sentido social dessa multiplicidade? Pesquisas anteriores já mostraram que o comportamento relacional múltiplo pode trazer vantagens para os indivíduos, pois facilita a obtenção de informações, recursos e apoios de ambientes relacionais distintos ao reduzir a homofilia de seus vínculos ${ }^{13}$. Entretanto, a multiplicidade em redes egocentradas obtidas por survey não diz respeito a uma maior circulação social do ego, mas às pessoas que participam de suas redes realizando múltiplas tarefas, auxiliando em diferentes situações de ajuda cotidiana. Nesse caso, portanto, a presença de multiplicidade tende a aumentar a redundância dos contatos de um dado ego e aponta para uma maior unificação (ou menor especialização) de suas redes temáticas. A existência de multiplicidade nesse artigo, portanto, está associada a graus mais elevados de homofilia e acesso mais restrito a redes diferentes que possam veicular novas informações e recursos, embora nenhuma das dimensões das redes deva ser considerada isoladamente.

$\mathrm{Na}$ literatura internacional que aborda comparativamente as redes egocentradas em áreas urbanas, uma importante referência é o estudo de Fischer e Shavit ${ }^{14}$. A partir de surveys realizados na Califórnia, EUA, nos anos 1970, e em Haifa, Israel, nos anos 1980, os autores demonstraram que as redes egocentradas encontradas nas duas regiões não diferem muito. Contudo, os israelenses apresentam, em média, redes mais densas, mais baseadas em parentesco e mais duradouras do que
[11] Ver McPherson, Miller, Smith-Lovin, Lynn e Cook, James. "Bir$\mathrm{ds}$ of a feather: homophily in social networks". Annual Review of Sociology,n. 27,pp.415-44, 2001, e Kadushin, Charles. "Some basic network concepts and propositions". In: Introduction to Social Network Theory. (www.scribd.com/doc/12748508/ Basic-Network-Concepts, 2004), acessado em 21/06/2011.

[12] Briggs, X (org.). The Geography of opportunity Race and Housing Choice in Metropolitan America. Washington, DC: Brookings Institution Press, 2005.

[13] Blokland, Talja. Urban Bonds. Londres: Basil Blackwell, a partir de classificação anterior de Ulf Hannertz; e Marques, op. cit., 2003.

[14] Fischer e Shavit, op.cit. 
[15] Grossetti, op.cit.

[16] Lonkila, op.cit.

[17] Ruan, D., Freeman, L., Dai, X., Pan, Y.e Zhang, W. “On the changing structure of social networks in urban China". Social Networks, vol. 19, 1997, pp. $75-89$.

[18] Lonkila, op. cit., p. 54 .

[19] Lee, R., Ruan, D. e Lai, G. “Social structure and support network in Beijing and Hong Kong". Social Networks, vol. 27, 2005, pp. 249-74.

[20]Bastani, S. "Family comes first: Men's and women's personal networks in Tehran". Social Networks, 29, 2007, pp.357-74. as norte-americanas. Grossetti ${ }^{15}$ replicou o estudo em Toulouse, França, encontrando similaridades na densidade média das redes. Estas foram explicadas a partir de uma suposta estabilidade das estruturas relacionais em países industrializados, levando Grossetti a concluir que as redes não são muito sensíveis a variações de contexto. $O$ autor também discutiu o papel do "capital relacional" no reforço de vários tipos de desigualdades, uma vez que encontrou em Toulouse diferenças nas estruturas das redes - considerando tamanho, densidade e homofilia - de acordo com diferentes grupos educacionais. Esses resultados foram confirmados tanto pela pesquisa sobre redes pessoais em São Paulo quanto pelas redes egocentradas discutidas neste artigo.

Outra análise interessante, desta vez baseada em redes pessoais totais, é o estudo de Lonkila, ${ }^{16}$ que analisou laços sociais no ambiente de trabalho como fonte de apoio social, entre trabalhadores russos e finlandeses, comparando os resultados com os obtidos por Ruan para a China ${ }^{17}$. Baseado em redes pessoais obtidas em Helsinque em 2003 e São Petersburgo em 2000, o autor descobriu que o passado socialista é ainda visível no papel central que colegas de trabalho desempenham nas redes de apoio social na China e na Rússia, diferentemente da Finlândia. O autor viu uma combinação complexa de tradições e experiências soviéticas pós-soviéticas, no caso da Rússia, sublinhando, contudo, que "os aspectos econômicos por si só dificilmente poderiam explicar as diferenças observadas"18.

De maneira similar, Lee, Ruan e Lai1 ${ }^{19}$ contrastaram as influências socialista e capitalista sobre redes egocentradas de apoio social em Pequim e Hong Kong, ambas sociedades urbanas modernas com patrimônio cultural similar, mas com diferentes estruturas econômicas e sociais. Os autores encontraram grandes semelhanças nas redes egocentradas de Pequim e Hong Kong, explicadas pela cultura chinesa em comum. Eles também destacaram os parentes próximos como a mais importantefonte de apoio social nas duas cidades. Uma diferença importante entre as cidades é a relevância muito maior da renda em Hong Kong do que em Pequim: pessoas de baixa renda em Hong Kong muito provavelmente não têm ninguém a quem recorrer para apoio social, ao contrário do observado em Pequim. Como veremos, a renda é também uma clivagem importante para explicar as redes pessoais e egocentradas no Brasil.

Bastani destacou outra dimensão importante nas redes de apoio social - a família ${ }^{20}$. Ao analisar redes pessoais de classe média na Teerã pós-revolução islâmica, Bastani mostra que homens e mulheres têm redes pessoais muito similares no que se refere ao tamanho e à porcentagem de parentes na rede, mas que diferem substancialmente na composição por sexo. Como observado em outros estudos - e também no caso das redes em São Paulo - , pessoas mais educadas têm redes maiores. Diferentemente de outros estudos, no entanto, os idosos têm redes 
maiores, o que é explicado por Bastani como um efeito da estrutura da família iraniana e pela maior permanência de filhos e irmãos nas redes, não importando sua idade. Várias dessas dinâmicas são explicadas pelo contexto social iraniano pós-revolucionário: devido às "restrições socioeconômicas impostas pela sociedade em geral, família e parentesco são locais de encontro onde a socialização dos jovens e do casamento são facilitadas" ${ }^{21}$. Além disso, de maneira similar ao que temos encontrado nas cidades brasileiras, os laços familiares são muito importantes para a alocação de recursos e para vários tipos de apoio social ao longo da vida do indivíduo.A relevância da família é também explicada pela população jovem e pela elevada taxa de fertilidade do Irã.

A única pesquisa sobre cidades brasileiras realizada anteriormente sobre redes egocentradas abordava especificamente as dimensões da homofilia e do localismo entre os habitantes da favela Céu de Estrelas, no Recife ${ }^{22}$. Os autores encontraram elevada homofilia, tanto de sexo quanto de idade e escolaridade, em especial entre os indivíduos com idade e escolaridade mais altas. A pesquisa indicou ainda um elevado localismo e forte presença de vizinhos e parentes nas redes dos indivíduos.

De forma geral, a literatura indica que as melhores situações sociais estão associadas a menores graus de homofilia. Essa associação se explica tanto porque heterofilia gera maior acesso a diversas dimensões sociais quanto porque aqueles em piores condições sociais tendem a dispor de menos recursos para produzir e manter relações mais heterofílicas - manter vínculos tem custos, dos mais variados tipos, emocionais e financeiros, por exemplo. A causalidade entre tipos de sociabilidade/ redes e condições sociais é múltipla, pois ao longo de suas trajetórias de vida os indivíduos constroem tanto suas redes quanto seus atributos de forma lenta, paulatina e na maioria das vezes não intencional. O nexo entre esses dois planos é dado por diferentes mecanismos relacionais ${ }^{23}$. Redes e atributos são fortemente impactados por mecanismos que envolvem recursos econômicos, processos educacionais e migratórios, a geografia urbana e a segregação e os acúmulos de vantagens e desvantagens nas trajetórias de vida ${ }^{24}$.

Agrande maioria desses mecanismos é circular e tende a ser cumulativa socialmente, impactando mais negativamente os indivíduos na razão direta de sua pobreza. Em decorrência da ação conjunta desses mecanismos, indivíduos mais pobres tendem a ter redes com maior homofilia, mais locais e mais recentes do que indivíduos não pobres. Como os dados daquela pesquisa não eram representativos para o conjunto da sociedade, ou mesmo para os indivíduos em situação de pobreza, este artigo procura confirmar os resultados em condições de representatividade estatística, mesmo considerando as diferenças entre redes egocentradas e redes pessoais.
[21] Bastani, op. cit., p.371.

\begin{abstract}
[22] Fontes, Breno e Eichner, Klaus. "A formação de capital social em uma comunidade de baixa renda". Redes - Revista Hispana para el análisis de Redes sociales, vol. 7, $\mathrm{n}^{\circ}$ 2, 2004, pp. 1-33, e Fontes, Breno. "Sobre a sustentabilidade das associações voluntárias em uma comunidade de baixa renda". Tempo social, vol. 15, $\mathrm{n}^{\circ}$ 1, 2003, pp.159-89.
\end{abstract} [23] Marques, Eduardo. "Mecanis-
mos relacionais". Revista Brasileira de
Ciências Sociais, vol. 22, n ${ }^{\circ} 64,2007$,
pp.157-61.

[24] Marques, op. cit., 2010. 
O survey de 2008 realizado no Rio de Janeiro e em São Paulo produziu uma ampla gama de informações sobre condições gerais de vida e de acesso a diversas políticas públicas. Foram entrevistadas 1.744 pessoas em pesquisa domiciliar, sendo 801 em São Paulo e 943 no Rio de Janeiro, todas chefes ou cônjuges do chefe do domicílio. A amostragem da pesquisa foi desenhada para ser representativa do conjunto da população, mas também dos $40 \%$ mais pobres de cada cidade, levando em conta as duas diferentes distribuições de renda.

Dentre os entrevistados, $45 \%$ eram homens e $55 \%$ mulheres. As idades variaram entre 16 e 90 anos, embora a maioria dos entrevistados tivesse entre 30 e 50 anos (46\%) e entre 21 e 30 anos (20\%). Pouco mais da metade dos entrevistados (55\%) tinha renda familiar mensal igual ou inferior a $\mathrm{R} \$ 950$ (em valores de junho de $2008 \mathrm{com}$ base na PNAD 2006) - esse era o corte de renda que aproximadamente separava os $40 \%$ mais pobres nas duas cidades - e $43 \%$ era natural de estado da federação diferente daquele de moradia.

Neste artigo são explorados apenas os resultados relativos às redes egocentradas de apoio social. Foram incluídas perguntas sobre as "relações que você mantém com pessoas próximas - como amigos, parentes, vizinhos, colegas de trabalho - e sobre como vocês se ajudam em algumas situações". Os entrevistados foram instados a responder sobre relações ligadas a ajudas:

- no dia a dia, emprestando mantimentos ou ferramentas, cuidando de seus filhos, etc.;

- dando dicas de emprego, informações sobre vagas, recomendações ou emprestando dinheiro, no caso de perda de emprego;

- auxiliando em problema grave de saúde em sua família, ou em situação de morte ou gravidez, transportando para hospital, marcando consultas ou ajudando financeiramente.

Para cada uma dessas perguntas, os entrevistados podiam responder até dez nomes, indicando atributos desses contatos: a) tipo da relação (parente, amigo, vizinho, colega de trabalho, igreja ou associação, conhecido ou ex-patrão); b) se mora ou não no mesmo bairro.

\section{Características gerais das redes}

As redes egocentradas de apoio são obviamente muito menores do que as redes totais, pelo próprio método de coleta das informações. Enquanto as redes pessoais levantadas em São Paulo apresentavam médias 
de 53 nós para os indivíduos pobres e 94 nós para indivíduos de classe média, no caso das redes egocentradas de apoio os indivíduos listaramem média 5,2 pessoas, sendo que em média 1,2 pessoa foi incluída em mais de uma rede, sugerindo 3,9 indivíduos como relação de apoio direto para cada entrevistado. A rede de apoio no caso de saúde tende a ser a maior, com 2,3 nós em média, seguida pela de cotidiano com 1,8 pessoa e a de emprego com 1,2 nó. Os tamanhos das três redes de ajuda são altamente correlacionados entre si, embora haja variações: indivíduos com grande rede de apoio em uma das situações tendem a ter redes grandes também nos demais tipos de ajuda. Isso indica que a sociabilidadee os atributos de cada indivíduo são os principais influenciadores das redes, e não a especificidade das ajudas. As redes de apoio social tendem a ser muito locais: $86 \%$ dos indivíduos são do próprio bairro, sendo a rede de ajudas no cotidiano a mais local (93\%) e a de emprego a menos local (80\%).

A homofilia de sexo (proporção de pessoas em uma dada rede que é do mesmo sexo do ego) é de $59 \%$, em média, mas é maior entre as mulheres (65\%, contra 53\% no caso das redes de homens), repetindo resultado já obtido no caso das redes pessoais em São Paulo. O localismo das redes de homens e mulheres é praticamente idêntico, mas as redes de emprego dos homens tendem a ser um pouco mais locais do que as das mulheres.

Ainda em termos médios, as redes eram compostas principalmente de parentes (57\%), seguidos de vizinhos (24\%) e de amigos (13\%), indicando concentração em vínculos homofílicos. Colegas e patrões aparecem em patamar muito inferior, com $2 \%$. Essa participação, entretanto, varia muito entre as três redes de apoio. A composição das redes egocentradas para solução de questões de saúde é concentrada em parentes (72\%), seguidos porvizinhos (11\%), colegas (6\%) e amigos $(4 \%)$. As redes para ajuda cotidiana são baseadas em parentes e vizinhos (39\% e 36\%), com os amigos representando $8 \%$. As redes mobilizadas para obtenção de emprego têm uma distribuição muito mais equânime, com parentes e amigos contribuindo com $24 \%$ e $21 \%$, respectivamente, e vizinhos, patrões e colegas em um patamar mais baixo - 10\%, 4\% e 3\%, respectivamente.

Informações referentes à obtenção de fato do emprego confirmam essas distribuições e, embora $29 \%$ dos entrevistados sustentem ter conseguido o emprego atual sozinhos, $27 \%$ dos entrevistados afirmaram que o obtiveram por intermédio de amigos, $16 \%$ por parentes, $6 \%$ por conhecidos e $4 \%$ porvizinhos. Concursos, ex-patrões, agências de empregos e anúncios variados respondiam a menos de 4\%. O papel das relações sociais é, portanto, evidente. Resultados similares foram obtidos nas redes pessoais em São Paulo, onde 66\% dos entrevistados obtiveram seu emprego por meio de redes, assim como em Guimarães ${ }^{25}$, que encontrou um percentual ainda mais elevado de obtenção
[25] Guimarães, Nadya. À procura de trabalho. Instituições do mercado e redes. Belo Horizonte: Argumentun, 2009. 
[26] Bidart, Caire e Lavenu, Daniel. "Evolution of personal networks and life events". Social Networks, $\mathrm{n}^{\circ} 27$, 2005, pp. 359-76. de empregos através de redes, $80 \%$ entre os indivíduos que procuravam emprego em agências.

Mas como as redes variam segundo atributos sociais? O restante desta seção explora a associação entre as redes egocentradas, atributos e processos sociais.

\section{Ciclo de vida}

Comecemos a análise pelo ciclo de vida ilustrado pelo Gráfico l, a seguir. Na verdade, trata-se de um exercício analítico, visto que não temos as redes dos indivíduos ao longo de suas vidas, mas as redes de indivíduos diversos em diferentes pontos do ciclo de vida.

A composição dessas três curvas (linha pontilhada) nos dá o total de vínculos, que aumenta até os 40 anos para cair lentamente até os 60 e intensamente a partir de então. O total de vínculos únicos (linha contínua preta) tende a se elevar até os 30 anos, seestabilizar até os 60 , para cair intensamente a partir de então. Em ambos os casos os dados indicam a expansão das redes com a entrada na vida adulta e a sua retração com o envelhecimento, padrão que é condizente com a literatura que associa tamanho das redes e ciclo de vida ${ }^{26}$. A diferença entre essas duas curvas indica a presença de vínculos múltiplos, ou seja, o fato de que um mesmo indivíduo é mobilizado para ajudar em mais de uma situação social. Como podemos ver, a diferença entre as duas curvas começa alta, mas se reduz paulatinamente em todas as faixas de idades. Isso indica que o ciclo de vida acarreta uma especialização das redes, aumentando gradativa mas continuamente a fragmentação das

\section{GRÁFICO I}

Tamanho das redes por faixa etária, Rio de Janeiro e São Paulo

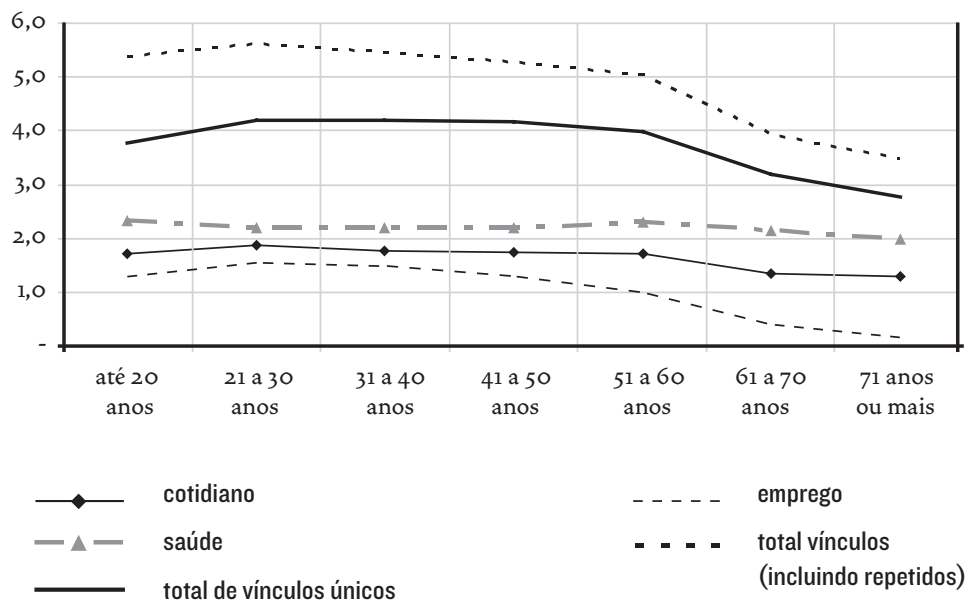


redes (ou rompendo a sua unificação). Se na juventude isso é contrabalançado pela elevação da atividade relacional, com o envelhecimento leva a um recolhimento relacional.

As três outras curvas do gráfico referem-se às redes temáticas. A rede de saúde se mantém relativamente constante em todas as faixas, com apenas uma pequena elevação próxima entre os 50 e 60 anos e uma leve queda depois dos 70 anos. A rede de emprego aumenta até os 40 anos acompanhando a entrada dos indivíduos no mercado de trabalho, para depois declinar. Vale notar como a redução das redes de emprego ocorre precocemente, inclusive considerando as idades típicas médias das aposentadorias no país. O mesmo tipo de dinâmica ocorre com a rede do cotidiano, mas a queda ocorre com menor intensidade e se inicia depois dos 60 anos. Observam-se, portanto, a trajetória de inserção social crescente e mais ampla na transição para a fase adulta, e a de crescente isolamento no caso dos mais velhos.

Essa interpretação é reforçada pela dinâmica do localismo. As redes de jovens com menos de 20 anos tendem a ser substancialmente locais (em média, $91 \%$ dos indivíduos presentes na rede dos jovens residem no mesmo bairro), mas a presença de indivíduos de fora do bairro aumenta a partir dos 20 anos e o localismo cai lentamente ao longo do ciclo da vida, chegando a $84 \%$ nas pessoas com 71 anos ou mais. Vale ressaltar que essa queda é explicada principalmente pela queda das redes de cotidiano e de emprego, que passam de $98 \%$ para $88 \%$ e de $86 \%$ para $77 \%$, respectivamente, entre o início e o fim do ciclo.

Mas como muda a composição relativa das redes ao longo das faixas etárias? A literatura sugere que a presença elevada de familiares e vizinhos, assim como redes mais locais e com mais alta multiplicidade, tende a ter padrões de vínculo mais homofílicos. O Gráfico 2, a seguir, apresenta essa informação.

Como podemos ver, a presença de parentes nas redes é sempre elevada, mas é maior nas primeiras idades, caindo à medida que o indivíduo entra na maturidade, e se elevando novamente a partir dos 60 anos. Os vínculos com amigos crescem relativamente até os 50 anos de idade, para cair a partir de então. E os vínculos com vizinhos, que se mantêm relativamente constantes até os 50 anos, crescem até os 60 anos (contrabalançando em parte a queda dos amigos), mas voltam a cair após essa idade. A combinação dos movimentos das três curvas reforça as dinâmicas já destacadas - amadurecimento, com a redução da família e o crescimento do papel dos amigos, e envelhecimento, com a redução dos amigos e dos vizinhos e o retorno da família. Isso é coincidente com o descrito pela literatura ${ }^{27}$, assim como com as dinâmicas observadas nas redes pessoais em São Paulo.

Todos esses resultados tendem ser similares para o Rio de Janeiro e para São Paulo.

[27] Como em Bidart e Lavenu, op. cit., e Blokland, op. cit. 


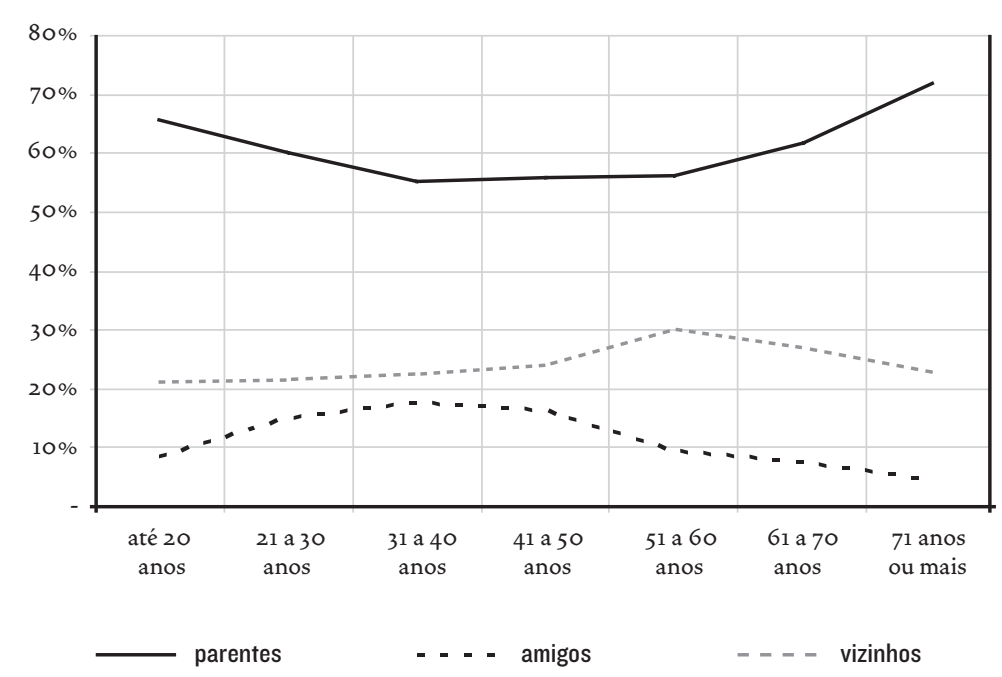

Fonte: Elaboração própria a partir de Cem/Iuperi, 2008.

\section{Renda e escolaridade}

Além dessas dinâmicas gerais, no entanto, grupos sociais distintos tendem a ter redes diferentes. De fato, as redes de indivíduos com rendas familiares mensais inferiores a $\mathrm{R} \$ 950$ têm em média 3,7 vínculos contra 4,2 vínculos dos indivíduos com rendas mais altas, especialmente pelo menor tamanho das redes de apoio para emprego e saúde. A distribuição da escolaridade segue a mesma tendência.

Um resultado similaréencontrado se abrimos as faixas de renda,embora com algumas nuances, como se pode ver no Gráfico 3. O tamanho das três redes de apoio tende a aumentar entre as faixas de renda muito baixa e média, mas entre as rendas mais elevadas o tamanho das redes e os vínculos únicos, apenas os vínculos únicos, caem levemente. A principal tendência com relação aos vínculos múltiplos é de manutenção, com pequena redução na faixa de renda mais elevada. O comportamento dessas curvas pode indicar dois processos sociais distintos mas combinados. Por um lado, a constituição e a manutenção de vínculos envolvem custos emocionais, operacionais e financeiros ${ }^{28}$, e por isso indivíduos muito pobres têm mais dificuldade de manter redes de apoio maiores. Por outro lado, entre as últimas faixas de renda, uma parcela substancial de bens e serviços é obtida de forma mercantilizada, não dependendo da constituição e manutenção de redes de apoio extensas. Isso é reforçado pela pequena importância relativa das ajudas cotidianas, assim como pela queda, nas rendas mais altas, do peso relativo da vizinhança, como 
veremos mais adiante. A rede de apoio que tende a variar menos entre grupos de renda é a relacionada à saúde, reforçando a estabilidade observada anteriormente. Embora para os grupos de maior rendimento os serviços de saúde em si tendam a ser obtidos através do mercado, uma série de auxílios mobilizados em crises de saúdeé prestada por apoio social em todos os grupos, como levar ou acompanhar doentes aos serviços de saúde ou ajudá-los posteriormente, em casa.

Os grupos sociais também variam substancialmente no que diz respeito ao localismo de suas redes. Como se pode ver no Gráfico 4, o localismo sobelevemente nas primeiras faixas de renda (o que talvez se deva apenas à variação amostral, considerando o tamanho dos grupos), mas a partir daí decresce continuamente. Esse decréscimo tem maior intensidade nas redes de emprego, que apresentam os mais baixos níveis de localismo dentre todas as redes. As redes de cotidiano, ao contrário, são sem dúvida alguma as mais locais para todos os grupos, o que é condizente inclusive com o tipo de auxílio prestado, geralmente porta a porta. Nessecaso também severifica uma elevação no início das faixas de rendimento (que pode se dever à variação amostral) e depois uma queda, mas de proporções muito inferiores à das demais curvas. No caso da saúde, a queda se acentua a partir das faixas intermediárias de rendimentos, o que talvez se deva à mercantilização das ajudas nas faixas mais elevadas. Resultados muito similares são obtidos com escolaridade, indicando que grupos sociais mais bem posicionados tendem a ter redes menos locais, resultado já encontrado para as redes pessoais em São Paulo.

O Gráfico 5 explora as diferenças de composição das redes por faixas de rendimento, comparando as duas faixas de renda polares ${ }^{29}$. Como podemos ver, a participação de parentes nas redes de apoio é elevada em ambas as faixas, embora seja um pouco menor acima de três salários mínimos. A presença de vizinhos acompanha a tendência e declina com a renda. A participação dos amigos, ao contrário, cresce bastante com a renda. Como sabemos, é possível sustentar a menor homofilia e o menor localismo das relações de amizade, quando comparadas com a família e a vizinhança. Assim, esses dados reforçam a mais ampla integração relacional de grupos sociais mais bem posicionados, mesmo para redes egocentradas de ajuda, repetindo os resultados das redes pessoais de São Paulo. Resultados similares são obtidos com a escolaridade, assim como desagregando as cidades.

A associação entre as características das redes e a maior ou menor integração social é comprovada pelos processos de migração. Entre os migrantes, e os migrantes nordestinos em particular, as redes tendem a ser menores, tanto nos vínculos totais quanto considerando apenas vínculos únicos. Isso é explicado por migrantes terem menores redes do cotidiano e do emprego, além de contarem com menor presença de vínculos múltiplos, sugerindo redes de ajuda mais seg-
[29] As faixas intermediárias de renda foram omitidas por seguirem o padrão das apresentadas. 
GRÁFICO 3

Tamanho das redes por renda familiar mensal per capita, Rio de Janeiro e São Paulo

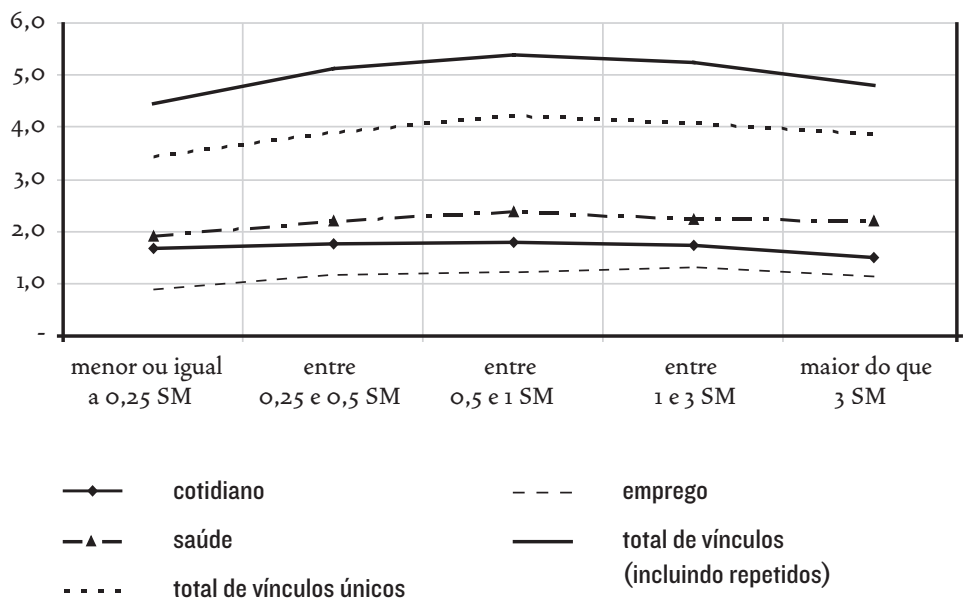

Fonte: Elaboração própria a partir de Cem/Iuperi, 2008.

\section{GRÁFICO 4}

Localismo nas redes por renda familiar mensal per capita, Rio de Janeiro e São Paulo

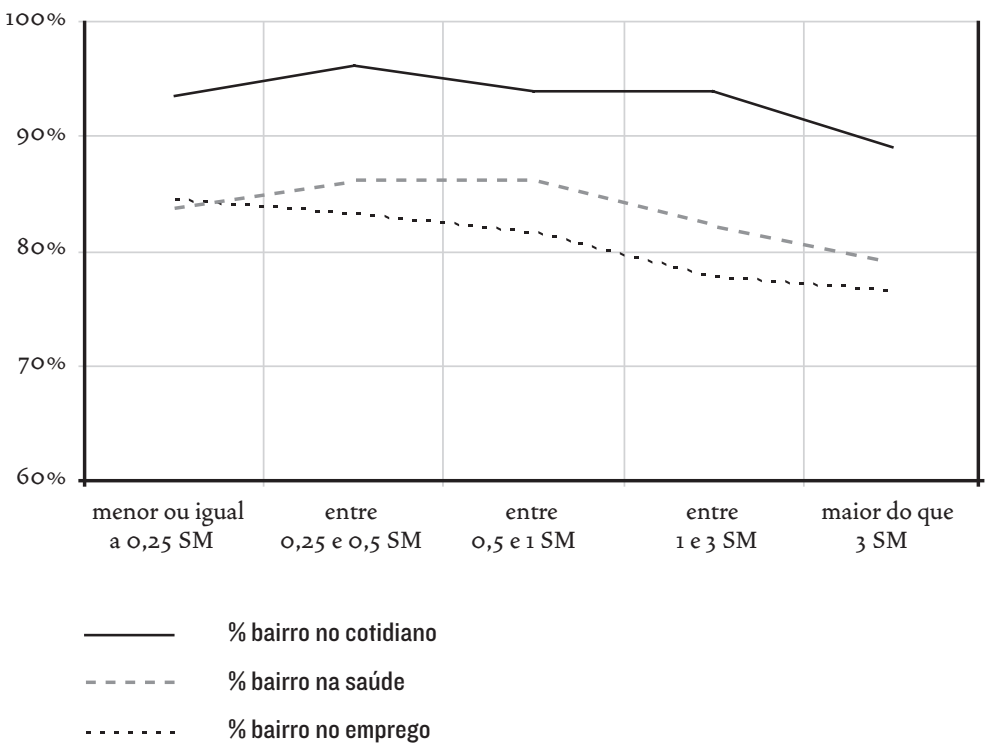

Fonte: Elaboração própria a partir de Cem/Iuperi, 2008.

mentadas. Suas redes são mais centradas em vizinhos e a presença de patrões é maior (embora também apresentem pequena dimensão absoluta). Os dados não mostraram efeitos significativos do tempo de migração, sugerindo pequena importância para os processos de assimilação dos migrantes.

Por fim, não há diferenças significativas por sexo. As mulheres têm redes de cotidiano e de saúde maiores do que os homens, mas não há 


\section{GRÁFICO 5}

Composição relativa das redes por rendimento familiar mensal per capita,

Rio de Janeiro e São Paulo ${ }^{30}$

Renda pc igual ou inferior a 0,25 SM

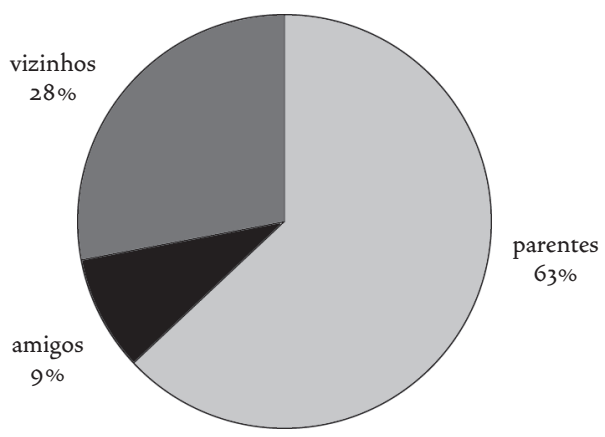

Renda pc superior a 3 SM

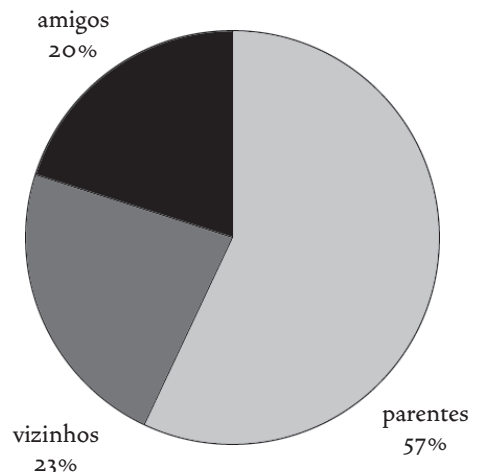

Fonte: Elaboração própria a partir de Cem/Iuperj, 2008.

diferenças significativas nos totais, tanto incluindo vínculos repetidos quanto considerando apenas vínculos únicos. As redes masculinas, por outro lado, tendem a ter mais amigos, menos vizinhos e menos patrões (apesar da pequena proporção destes). Não há diferenças sensíveis referentes a sexo quanto ao localismo. Essa relativa indiferenciação já havia sido encontrada nas redes pessoais estudadas em São Paulo e em estudos com dados do Social General Survey norte-americano31.
[30] As informações do survey também incluíam a presença de colegas (do trabalho, de igrejas e associações) e ex-patrões, mas a sua presença relativa foi omitida dos gráficos por ser em geral muito baixa (sempre inferiores a $2,5 \%$ ).

[31] Moore, op.cit.

\section{TIPOS DE REDES EGOCENTRADAS E ATRIBUTOS INDIVIDUAIS}

Por fim, considerando a grande variabilidade encontrada, decidimos classificar as redes, de modo a explorar conjuntamente todas as dimensões discutidas. Essa estratégia explicita como as redes variam e quais as principais clivagens que as diferenciam.

A partir das evidências apresentadas anteriormente com relação à variação entre as redes de pobres e não pobres (renda familiar média inferior e superior a $\mathrm{R} \$ 950$, respectivamente), decidimos proceder a uma classificação por análise de agrupamentos para cada um dos dois grupos ${ }^{32}$. A análise de agrupamentos considerou nove variáveis das redes de cada um dos entrevistados: total de vínculos, total de vínculos únicos, multiplicidade, proporções de parentes, vizinhos e amigos, além do localismo médio. O universo da análise incluiu 1.630 casos, sendo 816 não pobres, 814 pobres e 114 desconsiderados por apresentar problemas com alguma das variáveis. A análise resultou

[32] De forma a simplificar a apresentação, nos referimos a pobres e não pobres como "grupos sociais", embora evidentemente fossem necessárias muitas outras especificações para delimitar grupos no sentido da estrutura social. Trata-se apenas de uma forma rápida de distinguir esses dois grupos na descrição e na análise dos tipos de redes. 
[33] Todas essas análises foram realizadas no software Spss versão 13.0, utilizando o algoritmo K-means.

[34] Vale destacar que os rendimentos reportados como características dos grupos são rendas familiares médias mensais per capita, enquanto o limiar de diferenciação entre pobres e não pobres $(\mathrm{R} \$ 950)$ diz respeito à renda familiar média mensal utilizada como corte dos $40 \%$ mais pobres a partir da PNAD 2006. em quatro grupos para indivíduos pobres e cinco para não pobres33.A classificação foi realizada separadamente para cada grupo para permitir a obtenção de resultados específicos por grupo. A observação dos indicadores por tipo de rede, entretanto, sugeriu que a maior parte dos tipos de redes aparece tanto entre pobres quanto entre não pobres, enquanto apenas um tipo é específico dos não pobres. Esse resultado é muito importante, pois sugere que os mesmos princípios organizam internamente cada grupo, apesar de as redes e os atributos apresentarem obviamente valores absolutos diferentes.

Os tipos de redes são descritos a seguir, indicando a sua incidência por grupo social. Uma tabela ao final do artigo apresenta os indicadores médios por tipo.

\section{Redes grandes, com amigos e baixo localismo}

Esse tipo de rede está presente apenas entre os indivíduos não pobres ( 67 casos). São redes com tamanho muito grande ( 6,1 nós), principalmente pela presença de redes maiores na saúde (3,2 nós, as maiores redes de saúde, em média) e no emprego (2,2 nós, as maiores dentre os tipos), e multiplicidade média $(1,0)$. Observa-se elevada presença relativa de amigos ( $28 \%$ ) e baixa presença de vizinhos (12\%). Esse tipo de rede tem as menores proporções de indivíduos do próprio bairro, em especial no emprego - apenas 16\% — e na saúde - 38\%. Os indivíduos com essas redes têm a mais elevada renda per capita média entre os analisados $(\mathrm{R} \$ 1.413)$, assim como a melhor escolaridade 34 . A idade média no grupo é de 44 anos e as mulheres se encontram sobrerrepresentadas nesse tipo de rede.

\section{Redes grandes a médias, com amigos e elevado localismo}

Esse tipo de rede se encontra tanto entre indivíduos pobres (148 casos) quanto entre não pobres (170 casos). O tamanho das redes é grande $(4,9$ nós), mas inferior ao do tipo anterior e a multiplicidade é similar à do tipo anterior (cerca de 1,0).Vale reportarque esse tipo apresenta redes deemprego muito grandes entre pobres e não pobres:1,9 nó.A participação relativa mais importanteé dos amigos - cerca de $47 \%$ das redes de pobres e não pobres classificados neste tipo são compostos desse tipo de vínculo, percentual mais elevado entre todos os tipos -, sendo a presença de parentes (34\%) e de vizinhos (14\%) muito inferior às suas médias no conjunto dos entrevistados. O localismo é elevado, variando entre 83\% e 95\% dos vínculos. Os indivíduos com esse tipo de rede apresentam a mais baixa idade média ( 39 anos entre os pobres e 40 entre os não pobres). Tanto com relação à renda como à escolaridade, esse tipo de rede delimita indivíduos médios no interior de cada grupo social. Os homens 
se encontram sobrerrepresentados nesse tipo de rede, tanto entre os pobres quanto entre os não pobres.

\section{Redes médias a pequenas, principalmente de ajuda cotidiana, com vizinhos e localismo}

Esse tipo de rede também se mostra presente entre pobres ( 212 casos) e não pobres ( 213 casos). O tipo reúne redes entre médias (as dos não pobres, com média de 4,2 nós) e entre médias e pequenas (as dos pobres, com média de 3,8 nós), com multiplicidade muito elevada (as mais elevadas entre os casos estudados, 1,5 e 1,3 para pobres e não pobres, respectivamente). O tamanho das redes é explicado principalmente pelas grandes redes de cotidiano (as maiores dentre as estudadas, com 2,1 e 2,2 nós para pobres e não pobres, respectivamente). O tipo de participante mais presente são os vizinhos, com entre $68 \%$ e $65 \%$ dos vínculos, enquanto os parentes estão presentes com $26 \%$ e $28 \%$, respectivamente, o que corresponde a quase a metade da proporção média nos casos estudados. O localismo, por fim, é bastante elevado em termos médios, variando entre $81 \%$ e $98 \%$. As pessoas com esse tipo de rede têm rendas baixas - de $\mathrm{R} \$ 213$ e $\mathrm{R} \$ 870$ entre pobres e não pobres, assim como idades médias relativamente altas entre 45 e 49 anos, dentre pobres e não pobres. A escolaridade entre os pobres é a mais baixa dentre todos os desse grupo, sendo a segunda pior dentre os não pobres.

\section{Redes pequenas, principalmente de saúde, com parentes e localismo}

Esse tipo de rede egocentrada novamente se faz presente tanto entre pobres ( 371 casos) quanto entre não pobres ( 341 casos). Trata-se do tipo de rede mais frequente. O tamanho é pequeno - 3,6 nós entre os pobres e 4 nós entre os não pobres - ea multiplicidadé éalta - 1,2 nó.Apesar de pequenas, essas redes incluem as maiores redes de saúde, em média, ao mesmo tempo que as redes de emprego e cotidiano estão, ao contrário, dentre as menores. Essas redes são baseadas quase exclusivamente em parentes - $86 \%$ para não pobres e $85 \%$ para pobres - , sendo amigos evizinhos pouco presentes (3\% e 4\% de amigos e $8 \%$ e $7 \%$ devizinhos). O localismoé o mais alto dentre todos os tipos de redes, variando entre $92 \%$ e $99 \%$ entre tipos de redes de apoio. Os rendimentos médios desse tipo são os mais baixos, tanto entre pobres quanto entre não pobres. $\mathrm{O}$ mesmo se verifica com a escolaridade, sugerindo que quem tem esse tipo de rede tem situação social relativamente pior, independente do grupo social. Isso reforça a associação entre as piores condições sociais, elevada homofilia e localismo. 
Esse tipo de rede caracteriza 83 casos entre os pobres e 46 entre os não pobres. Reúne redes pequenas - 3,7 nós entre os pobres e 2,6 entre os não pobres, em especial pelas pequenas redes de emprego e cotidiano. As redes apresentam baixa multiplicidade (1 nó entre os pobres e 0,5 entre os não pobres, em média) e alta presença de parentes, embora inferior à do tipo anterior - 79\% entre não pobres e $86 \%$ entre pobres. Mas a principal diferença com o grupo anterior está no localismo, que nesse caso é baixo, variando de $17 \%$ para o emprego entre os não pobres (e $19 \%$ entre os pobres) a $64 \%$ para o cotidiano entre os pobres (e $50 \%$ entre os não pobres), todos muito inferiores às médias dos casos estudados. Os indivíduos com redes desse tipo têm renda média de $\mathrm{R} \$ 248$ entre os pobres e $\mathrm{R} \$ 955$ entre os não pobres, a renda média mais elevada dentre os pobres e a segunda mais alta entre os não pobres. As distribuições de escolaridade também são relativamente altas (a melhor dentre os pobres).

A Tabela 1 sintetiza as informações anteriores, reordenando os tipos não mais em ordem decrescente de tamanho, mas em ordem decrescente de rendimento familiar per capita médio. Esse procedimento explicita os elementos que organizam a variabilidade das redes, tanto para pobres quanto para não pobres.

Como podemos ver, as melhores condições sociais referentes a renda, escolaridade e emprego estão associadas a baixo localismo. Em ambos os casos também estão sub-representados vizinhos, sendo que entre os não pobres estão sobrerrepresentados os amigos e entre os pobres os parentes. Nesse último caso, a alta presença relativa de parentes pode se dever ao pequeno tamanho das redes. $\mathrm{O}$ tamanho das redes, entretanto, parece não fazer muita diferença em si. As piores condições, no entanto, estão associadas a localismo e predominância de vizinhos, elementos associados potencialmente a maior homofilia.

Os indivíduos com melhores condições, tanto entre pobres quanto entre não pobres, dispõem de todos os tipos de redes de apoio, mas, se nos dirigimos às piores condições, quase desaparecem as redes de apoio para emprego (tanto causa quanto consequência das piores condições). A rede de apoio de saúde parece ser o tipo de rede de apoio mínima, presente mesmo nas piores situações, e que acaba por sobressair entre os indivíduos com piores condições de renda e escolaridade, tanto pobres quanto não pobres.

Pode-se imaginar queessa associação entre redes e atributos tende a produzir circularidades negativas que certamente contribuem para reproduzir as desigualdades sociais e a pobreza, mesmo entre os mais pobres, confirmando resultados das redes pessoais em São Paulo. 


\begin{tabular}{|c|c|c|c|c|c|c|}
\hline \multirow{2}{*}{ Redes } & \multicolumn{3}{|c|}{ Entre os não pobres } & \multicolumn{3}{|c|}{ Entre os pobres } \\
\hline & $\begin{array}{l}\text { Renda pc } \\
\text { (R\$) }\end{array}$ & $\begin{array}{c}\% \\
\text { curso superior }\end{array}$ & $\begin{array}{l}\text { \% com carteira, } \\
\text { funcionário público } \\
\text { ou proprietário }\end{array}$ & $\begin{array}{l}\text { Renda pc } \\
\text { (R\$) }\end{array}$ & $\begin{array}{c}\% \text { com mais do } \\
\text { que Ensino } \\
\text { Fundamental I }\end{array}$ & $\begin{array}{c}\% \\
\text { desempregados }\end{array}$ \\
\hline $\begin{array}{l}\text { Grandes com amigos } \\
\text { e baixo localismo }\end{array}$ & 1.414 & 27 & 57 & - & - & - \\
\hline $\begin{array}{l}\text { Pequenas com parentes } \\
\text { e baixo localismo }\end{array}$ & 955 & 20 & 59 & 248 & 56 & 23 \\
\hline $\begin{array}{l}\text { Grande/média com amigos } \\
\text { e localismo }\end{array}$ & 874 & 17 & 40 & 230 & 48 & 28 \\
\hline $\begin{array}{l}\text { Médias/pequenas no } \\
\text { cotidiano com vizinhos } \\
\text { e localismo }\end{array}$ & 870 & 16 & 42 & 213 & 47 & 30 \\
\hline $\begin{array}{l}\text { Pequenas na saúde com } \\
\text { parentes e localismo }\end{array}$ & 700 & 11 & 45 & 202 & 44 & 34 \\
\hline
\end{tabular}

Fonte: Elaboração própria a partir de Cem/Iuperj, 2008

\section{CONCLUSÃo}

Os resultados indicaram que, embora as redes egocentradas de apoio social tendam a ser muito menores e menos complexas do que as redes pessoais totais, elas variam segundo os mesmos princípios. As redes tendem a crescer até a idade adulta e a diminuir durante a velhice, em especial as redes de apoio para obtenção de emprego. Quanto à composição, as redes de jovens e de idosos tendem a apresentar maior presença relativa de parentes. Por outro lado, a presença de vizinhos e, principalmente de amigos, cai após os 60 anos de idade. Pode-se dizer, portanto, que tanto jovens quanto idosos apresentam redes com graus mais elevados de homofilia. Essa dinâmica etária, entretanto, se superpõe a outras. Uma das mais importantes está ligada a diferentes grupos sociais, pois mecanismos relacionais facilitam a construção e a manutenção de vínculos no caso de grupos sociais mais bem posicionados. De forma geral, quando comparadas com as redes de indivíduos de menor renda, as redes de pessoas de maior renda tendem a ser maiores, menos locais e mais baseadas em amigos, em prejuízo da família e dos vizinhos. Esses resultados confirmam homofilia mais elevada entre indivíduos mais pobres, o que certamente gera importantes consequências referentes à reprodução das desigualdades.

A tipologia desenvolvida confirmou a existência de intensa heterogeneidade interna a cada grupo social. Entretanto, os resultados demonstraram a existência de tipos similares de redes entre pobres e não pobres, 
Recebido para publicação

em 14 de abril de 2011.

\section{NOVOSESTUDOS}

\section{CEBRAP}

90 , julho 2011

pp. $65-83$ apesar das evidentes diferenças de atributos sociais, o que sugere a operação dos mesmos mecanismos relacionais entre pobres e não pobres. No interior de cada grupo, os indivíduos mais bem posicionados socialmente tendem a contar com redes potencialmente menos homofílicas, menos locais e menos baseadas em vizinhos e em familiares, assim como em apoios cotidianos. Essa associação entre homofilia e piores condições sociais contribui provavelmente para circularidades, perpetuando as desigualdades de oportunidades relacionais e de atributos sociais.

EDUARDO MARqUES é professor livre-docente do Departamento de Ciência Política da USP e pesquisador do Centro de Estudos da Metrópole do Cebrap (CEM/Cebrap).

RENATA BICHIR é doutora em Ciência Política pelo IESP-UERJ e pesquisadora do Centro de Estudos da Metrópole do Cebrap (CEM/Cebrap).

ANEXO

Indicadores médios por tipos de redes, Rio de Janeiro e São Paulo

\begin{tabular}{|c|c|c|c|c|c|c|c|c|c|c|c|}
\hline \multicolumn{12}{|c|}{ Renda familiar mensal superior a $\mathrm{R} \$ 950$} \\
\hline Redes & $\begin{array}{l}\text { Total de } \\
\text { vínculos } \\
\text { únicos }\end{array}$ & $\begin{array}{c}\text { nós no } \\
\text { cotidiano }\end{array}$ & $\begin{array}{l}\text { nós para } \\
\text { emprego }\end{array}$ & $\begin{array}{l}\text { nós para } \\
\text { saúde }\end{array}$ & $\begin{array}{c}\text { nós } \\
\text { múltiplos }\end{array}$ & $\begin{array}{c}\% \\
\text { parentes }\end{array}$ & $\begin{array}{c}\% \\
\text { amigos }\end{array}$ & $\begin{array}{c}\% \\
\text { vizinhos }\end{array}$ & $\begin{array}{l}\% \text { bairro } \\
\text { cotidiano }\end{array}$ & $\begin{array}{l}\% \text { bairro } \\
\text { emprego }\end{array}$ & $\begin{array}{l}\text { \% bairro } \\
\text { saúde }\end{array}$ \\
\hline $\begin{array}{l}\text { Grandes com amigos } \\
\text { e baixo localismo }\end{array}$ & 6,1 & 1,8 & 2,2 & 3,2 & 1,0 & 52 & 28 & 12 & 70 & 16 & 38 \\
\hline $\begin{array}{l}\text { Grande/média com } \\
\text { amigos e localismo }\end{array}$ & 4,9 & 1,8 & 1,9 & 2,3 & 1,1 & 33 & 47 & 14 & 94 & 85 & 93 \\
\hline $\begin{array}{l}\text { Médias/pequenas no } \\
\text { cotidiano com vizinhos } \\
\text { e localismo }\end{array}$ & 4,2 & 2,2 & 1,2 & 2,1 & 1,3 & 28 & 5 & 65 & 98 & 88 & 83 \\
\hline $\begin{array}{l}\text { Pequenas na saúde com } \\
\text { parentes e localismo }\end{array}$ & 4,0 & 1,6 & 1,1 & 2,5 & 1,2 & 85 & 4 & 7 & 98 & 92 & 95 \\
\hline $\begin{array}{l}\text { Pequenas com parentes } \\
\text { e baixo localismo }\end{array}$ & 2,6 & 0,7 & 0,7 & 1,7 & 0,5 & 79 & 9 & 4 & 50 & 17 & 34 \\
\hline Total & 4,3 & 1,8 & 1,3 & 2,4 & 1,1 & 57 & 15 & 24 & 93 & 78 & 84 \\
\hline \multicolumn{12}{|c|}{ Renda familiar mensal igual ou inferior a $\mathrm{R} \$ 950$} \\
\hline $\begin{array}{l}\text { Grande/média com } \\
\text { amigos e localismo }\end{array}$ & 4,9 & 1,8 & 1,9 & 2,2 & 1,0 & 34 & 48 & 14 & 95 & 83 & 89 \\
\hline $\begin{array}{l}\text { Médias/pequenas no } \\
\text { cotidiano com vizinhos } \\
\text { e localismo }\end{array}$ & 3,8 & 2,1 & 1,1 & 2,0 & 1,5 & 26 & 3 & 68 & 97 & 88 & 81 \\
\hline $\begin{array}{l}\text { Pequenas na saúde com } \\
\text { parentes e localismo }\end{array}$ & 3,7 & 1,7 & 0,9 & 2,1 & 1,0 & 72 & 7 & 17 & 64 & 19 & 25 \\
\hline $\begin{array}{l}\text { Pequenas com parentes } \\
\text { e baixo localismo }\end{array}$ & 3,6 & 1,6 & 0,9 & 2,3 & 1,2 & 86 & 3 & 8 & 99 & 95 & 97 \\
\hline Total & 3,9 & 1,8 & 1,1 & 2,2 & 1,2 & 59 & 12 & 26 & 94 & 83 & 84 \\
\hline
\end{tabular}

